\title{
Fracture Propagation and Hydraulic Properties of a Coal Floor Subjected to Thick-Seam Longwalling above a Highly Confined Aquifer
}

\author{
Shaodong Li $\mathbb{D}^{1},{ }^{1}$ Gangwei Fan $\mathbb{D}^{1,2}$ Dongsheng Zhang, ${ }^{3}$ Shizhong Zhang $\mathbb{D},{ }^{1}$ Liang Chen $\left(\mathbb{D},{ }^{3}\right.$ \\ Shang Ren, ${ }^{1}$ and Yibo Fan ${ }^{1}$ \\ ${ }^{1}$ School of Mines, China University of Mining \& Technology, No. 1 University Road, Xuzhou, Jiangsu 221116, China \\ ${ }^{2}$ Key Laboratory of Deep Coal Resource Mining, China University of Mining \& Technology, Ministry of Education, No. 1 \\ University Road, Xuzhou, Jiangsu 221116, China \\ ${ }^{3}$ State Key Laboratory of Coal Resources and Safe Mining, China University of Mining \& Technology, No. 1 University Road, Xuzhou, \\ Jiangsu 221116, China
}

Correspondence should be addressed to Gangwei Fan; fangw@cumt.edu.cn

Received 7 December 2020; Accepted 13 June 2021; Published 3 July 2021

Academic Editor: Yong Liu

Copyright (c) 2021 Shaodong Li et al. This is an open access article distributed under the Creative Commons Attribution License, which permits unrestricted use, distribution, and reproduction in any medium, provided the original work is properly cited.

\begin{abstract}
The high-pressure and water-rich confined aquifer occurring in the Ordovician limestone sequence poses great threats to the routine production of underground longwall mining. Considering the intense cooperation of mining disturbance and water pressure, water-conducting fractures within a coal seam floor can connect the lower aquifer and upper goaf, and this hydraulic behavior is considered the root of water inrush hazard and water loss or contamination. In this paper, the panel 4301 of the Longquan coal mine serves as the case where the panel works closely above the floor with high water pressure. By the combination of physical and numerical modelling approaches, the variation characteristics of fracture development and volumetric strain of floor rocks subjected to mining disturbance are analyzed. A numerical computation model is constructed based on the volumetric strain-permeability equation obtained by curve fitting, and on such basis, the impacts of different mining parameters on floor rock permeability are studied. The results show that the floor rocks experience fracture generation, extension, and convergence procedures as the workface advances along the longitudinal direction, and fractures appearing in front of the workface are more developed. In the whole process of coal seam extraction, the volumetric strain profile exhibits " $\Lambda$ " shape and an inverted saddle shape before and after overburden strata collapse. By controlling a single variable, the paper reveals that panel height is of greater impact on floor permeability changes than panel length and panel width.
\end{abstract}

\section{Introduction}

Coal resource plays an important role in China's economic development, and the coal mines in North China contribute to $90 \%$ of the total output. The safety production of coal mines in such an extensive area attracts much attention [1, 2]. However, in the base floor of north coalfields, there exists the Ordovician karst aquifer, and because of its high pressure and water abundance, groundwater loss or contamination or even mine flooding catastrophe is likely to occur as long as mining-induced hydraulic channels bridge the immediate floor and the aquifer in Ordovician limestone. Long-term and large-scale coal resource exploitation triggers substantial fractures between the coal seam floor and confined aquifer. Such connective fractures can drastically affect groundwater equilibrium, and further, the loss of water resource would disturb the subsurface flow regime and give rise to irreversible ecological deterioration [3-5]. Currently, a great number 
of coal-producing enterprises are leaving traditional mode and transforming to green and water-conserved mining mode. In this context, the study on deformation, failure, and hydraulic property variation of a coal seam floor above a highly confined aquifer is of great significance for providing best water-conserved mining practice for North China.

In recent years, the failure mechanism of a longwall panel floor above a confined aquifer attracted great concerns [6-9]. For example, Liu et al. [10] conducted mathematical modelling to describe the failure of an inclined coal seam floor above confined water and calculated the failure depth after mining based on semi-infinite element theory. Lu and Wang [11] revealed that rock mass fracturing may experience three steps with the mined-out area enlarging, which included minor fracture initiation as the first step, fracture extension as the second, and fracture propagation through the whole rock mass as the third. By means of physical and numerical modelling methods, Hu et al. [12] studied the delay behavior of coal seam floor failure under the coupling effect of confined water and connective cracking regime. Liang et al. [13] analyzed coal seam floor failure under the impacts of mining-induced stress redistribution and uneven pressure caused by confined water; by establishing a two-dimensional hydraulic model and a key stratum stability model, the theoretical profile of failure and stable areas of an inclined floor was obtained. Such studies are mainly associated with the failure depth of a coal seam floor subjected to low water pressure or with the propagation profile of rock mass fractures. In fact, for the case where the longwall panel is just located closely above the highly confined aquifer in the paper, it is more challenging on account of larger water pressure, higher confined water-conducting zone, and greater risk of water inrush into the workface. So considering the safety of longwall panels exposed to such extreme circumstances, it is important to understand the mechanism of coal seam floor deformation and failure.

At present, many scholars have obtained various strainpermeability curves by means of experiments [14-18]. However, such studies were mainly based on small-scale rock samples, and for those cases where mining operations work above a highly confined aquifer, the whole panel floor shall be considered together. In this context, mining parameters are critical factors contributing to floor permeability enhancement. In fact, research achievements in this field are limited, and most of them are associated with the overburden rather than floor rocks [19-21]. For example, Khanal et al. [22] studied how different geometries of the longwall panel affect the permeability of overburden strata by means of numerical modelling and obtained the corresponding variation law of permeability. It is inappropriate to directly apply such laws like this kind to the coal seam floor. Therefore, the study of mining parameters affecting floor permeability in the case of a highly confined aquifer is necessary for the in situ preservation of deep-seated confined water.

From the perspective of water-conserved mining, the paper takes panel 4301 of the Longquan coal mine as the geological background. At first, panel floor fracturing and permeability variation with workface advancing are studied using physical modelling. A function between the volumetric strain and permeability of floor rocks is obtained by curve fitting, which is considered suitable to such geological conditions of the Longquan coal mine. Then, a numerical modelling approach is employed to evaluate the impact of panel height, panel width, and plane length on floor permeability. Such works can be taken as reference for profiling the permeability variation of a coal seam floor above a highly confined aquifer.

\section{Geological Overview}

There is no limestone outcrop in the Longquan coalfield. Due to the existence of thick overlying strata and no lateral recharge from atmospheric precipitation and surface runoffs, the water entering karst rock groups is derived from the infiltration of atmospheric precipitation through the northwestern, western, and southwestern carbonate outcrops, with some other derived from the leaking recharge across the major dislocation. As a result, the water flow path is of a significant distance extending from the south and northwest to southeast. At the same time, there is no natural discharge path in such an area, but only artificial water supply wells that can be considered discharge points. As a whole, Ordovician limestone water flowing from the west to east and reaching panel 4301 is the only exhalent region in the paper. The floor of the no. 4 coal seam in the Longquan coal mine bears Ordovician limestone water inrush coefficient of $0.036 \sim 0.097$ $\mathrm{MPa} / \mathrm{m}$. The coalfield can be divided into 7 areas, as shown in Figure 1. According to the critical value of water inrush coefficient of $0.06 \mathrm{MPa} / \mathrm{m}$, it can be seen from Figure 1(a) that there are water inrush risks in the northeast area and panel 4301 of the mine. Panel 4301 is $720 \mathrm{~m}$ in length and $250 \mathrm{~m}$ in width, using a top coal caving method to extract the coal seam with height $6.47 \mathrm{~m}$. The elevation of the panel ranges from $+525.2 \mathrm{~m}$ to $+630.5 \mathrm{~m}$. Affected by the confined limestone water in Taiyuan and Ordovician formations, the panel floor suffers high water pressure that is 4.97 6.29 $\mathrm{MPa}$ in the natural state. The lithological sequence of panel 4301 is exhibited in Figure 1(b).

\section{Deformation and Failure Characteristics}

3.1. Physical Modelling. In order to understand the stress condition and failure rule of the coal seam floor subjected to mining disturbance and high water pressure as well as the caving and movement behavior of overburden strata, the physical modelling method is employed here to emulate the phased excavation process. For constructing the physical model, various parameters of each stratigraphic unit are calculated via similarity theory. Then, a self-developed high-pressure water simulator is adopted.

According to the fundamental principles of similarity theory, the ratio of similitude is $100: 1$ in geometry, 10:1 in time, $1.7: 1$ in volume-weight, and $170: 1$ in both elastic modulus and strength. Such a physical model is mainly composed of sand, lime, gypsum, and pure water. The detailed contents and proportions of each ingredient are listed in Table 1.

Based on the experimental platform, a plane physical model with $2500 \mathrm{~mm}, 2200 \mathrm{~mm}$, and $30 \mathrm{~mm}$ in length, height, and thickness, respectively, is established. This model emulates the $226 \mathrm{~m}$ thick lithological sequence, and the above 


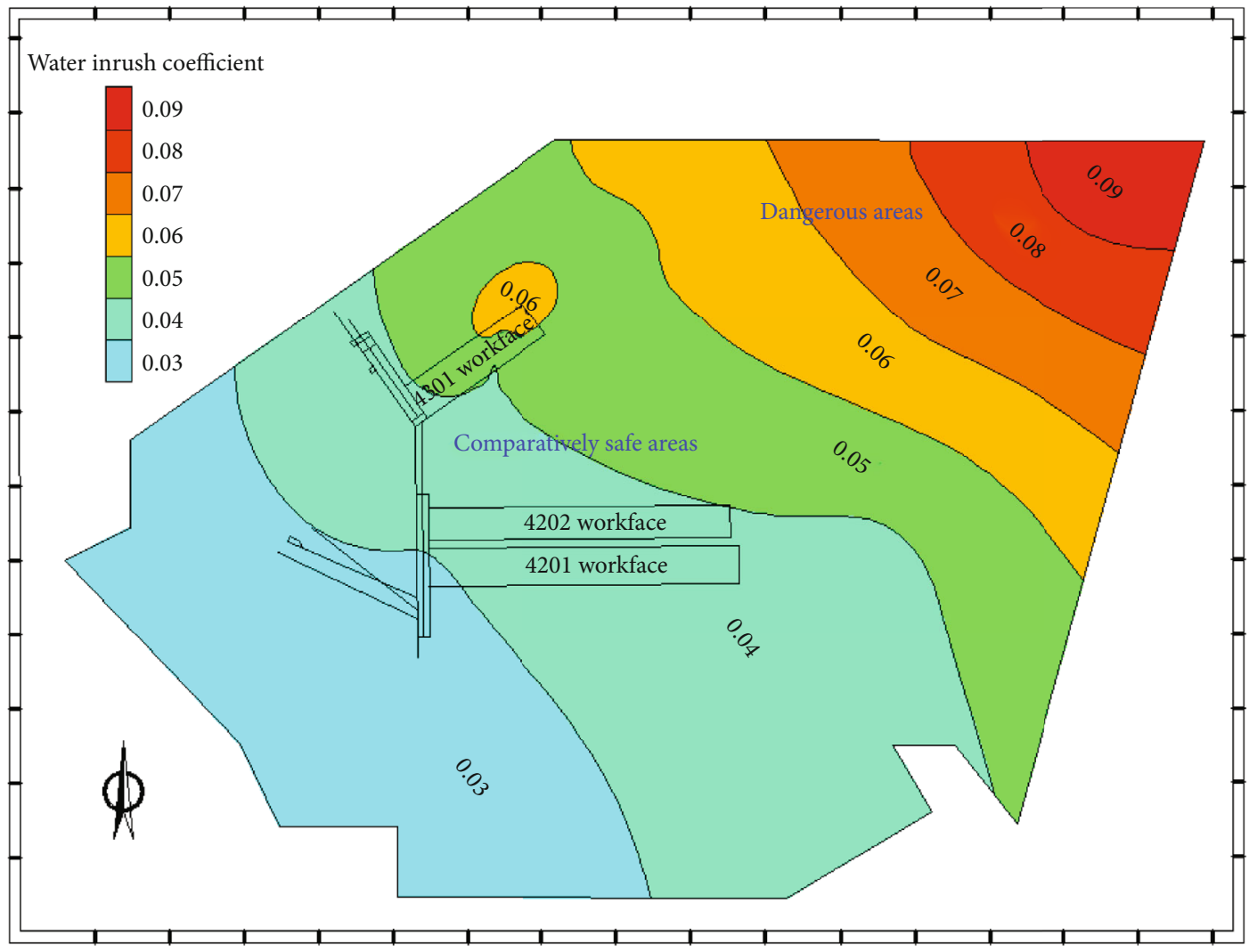

(a)

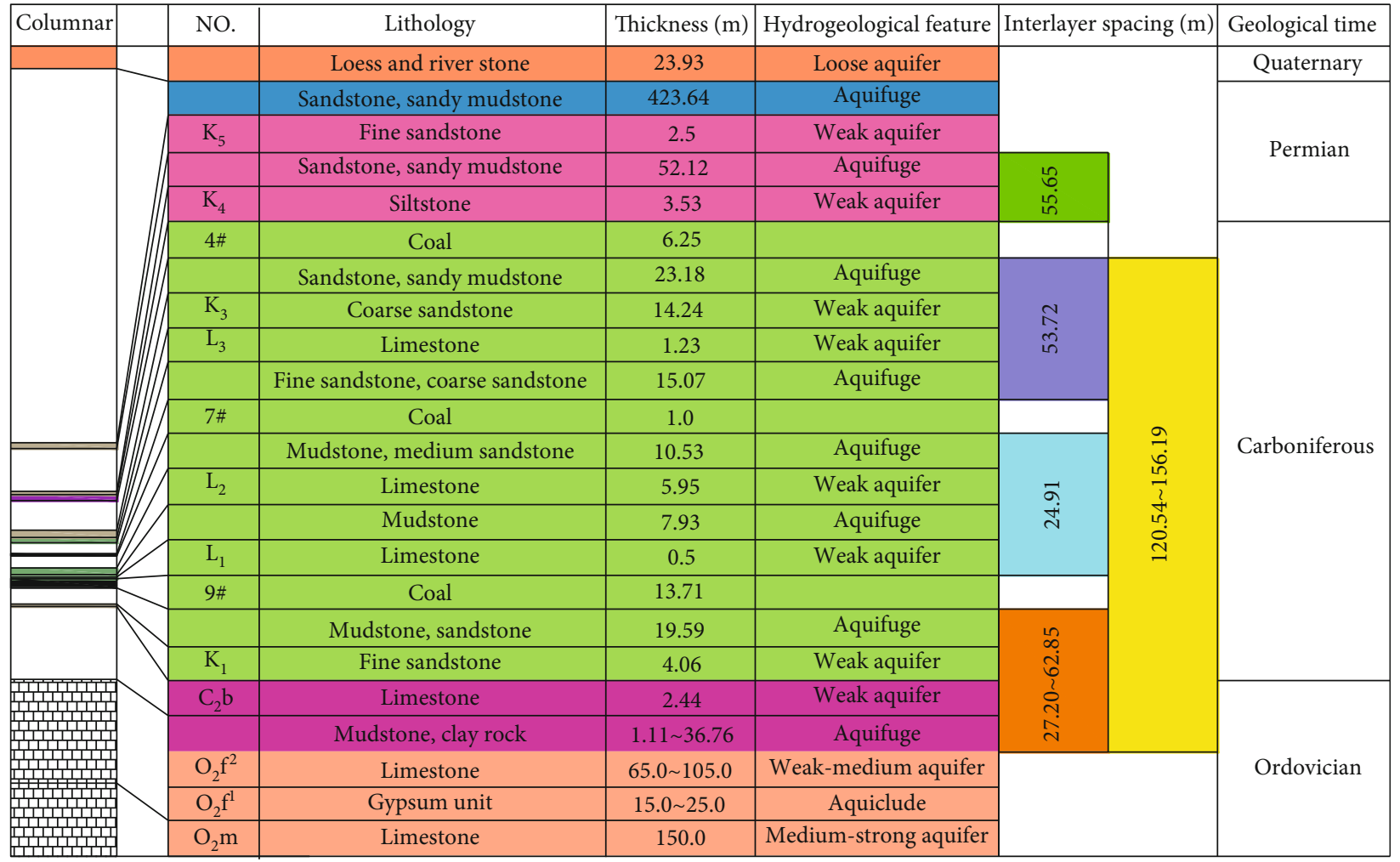

(b)

Figure 1: Geological data of the Longquan coal mine: (a) contour map of Ordovician limestone water inrush coefficient of the no. 4 coal seam in the Longquan coal field; (b) lithological sequence of the 4301 panel. 
TABLE 1: Parameters and material ratio of the physical model.

\begin{tabular}{|c|c|c|c|c|c|c|c|c|}
\hline \multirow[b]{2}{*}{ No. } & \multirow[b]{2}{*}{ Lithology } & \multirow{2}{*}{$\begin{array}{l}\text { Thickness } \\
(\mathrm{m})\end{array}$} & \multicolumn{2}{|c|}{ Strength $(\mathrm{MPa})$} & \multirow{2}{*}{$\begin{array}{l}\text { Simulated thickness } \\
\qquad(\mathrm{cm})\end{array}$} & \multicolumn{3}{|c|}{ Quality (kg) } \\
\hline & & & $\begin{array}{c}\text { Uniaxial } \\
\text { compression }\end{array}$ & $\begin{array}{l}\text { Uniaxial } \\
\text { tension }\end{array}$ & & Sand & Lime & Gypsum \\
\hline 1 & Sandy mudstone & 16 & 18.3 & 0.9 & 16 & 168 & 27.2 & 28.8 \\
\hline 2 & Siltstone & 21 & 29.4 & 1.6 & 21 & 214.2 & 23.1 & 37.1 \\
\hline 3 & Mudstone & 3 & 16.2 & 0.7 & 3 & 33.6 & 2.4 & 5.4 \\
\hline 4 & Sandy mudstone & 9 & 18.3 & 0.9 & 9 & 94.5 & 15.3 & 16.2 \\
\hline 5 & Fine sandstone & 3 & 37.6 & 2.1 & 3 & 34.5 & 4.5 & 4.5 \\
\hline 6 & Sandy mudstone & 12 & 18.3 & 0.9 & 12 & 126 & 20.4 & 21.6 \\
\hline 7 & Mudstone & 2 & 16.2 & 0.7 & 2 & 22.4 & 1.6 & 3.6 \\
\hline 8 & Sandy mudstone & 16 & 18.3 & 0.9 & 16 & 168 & 27.2 & 28.8 \\
\hline 9 & Siltstone & 3 & 29.4 & 1.6 & 3 & 30.6 & 3.3 & 5.3 \\
\hline 10 & Mudstone & 4 & 16.2 & 0.7 & 4 & 44.8 & 3.2 & 7.2 \\
\hline 11 & Sandy mudstone & 4 & 18.3 & 0.9 & 4 & 42 & 6.8 & 7.2 \\
\hline 12 & Carbonaceous mudstone & 2 & 24.8 & 1.2 & 2 & 22.4 & 3.2 & 6.3 \\
\hline 13 & $\begin{array}{l}\text { Aluminum-containing } \\
\text { mudstone }\end{array}$ & 5 & 26.9 & 1.4 & 5 & 54.5 & 3.2 & 6.2 \\
\hline 14 & Sandy mudstone & 7 & 18.3 & 0.9 & 7 & 73.2 & 11.9 & 12.6 \\
\hline 15 & Siltstone & 4 & 29.4 & 1.6 & 4 & 44.2 & 4.4 & 7.1 \\
\hline 16 & 4\# coal & 6 & 10 & 0.6 & 6 & 61.8 & 10.8 & 11.3 \\
\hline 17 & Fine sandstone & 6 & 37.6 & 2.1 & 6 & 69 & 9 & 9 \\
\hline 18 & Sandy mudstone & 12 & 18.3 & 0.9 & 12 & 126 & 20.4 & 21.6 \\
\hline 19 & Fine sandstone & 5 & 37.6 & 2.1 & 5 & 57.5 & 7.5 & 7.5 \\
\hline 20 & Coarse sandstone & 14 & 47.8 & 3.5 & 14 & 144.6 & 30.8 & 31.2 \\
\hline 21 & L3 limestone & 1 & 38.3 & 2.9 & 1 & 9.6 & 1.8 & 1.7 \\
\hline 22 & Fine sandstone & 10 & 37.6 & 2.1 & 10 & 115 & 15 & 15 \\
\hline 23 & Siltstone & 5 & 29.4 & 1.6 & 5 & 55.6 & 5.5 & 21.2 \\
\hline 24 & Medium sandstone & 5 & 42.6 & 3.2 & 5 & 53.4 & 11 & 12.1 \\
\hline 25 & Mudstone & 6 & 16.2 & 0.7 & 6 & 67.2 & 4.8 & 10.8 \\
\hline 26 & L2 limestone & 6 & 38.3 & 2.9 & 6 & 57.6 & 10.8 & 10.5 \\
\hline 27 & Mudstone & 8 & 16.2 & 0.7 & 8 & 89.6 & 6.4 & 14.4 \\
\hline 28 & L1 limestone & 1 & 38.3 & 2.9 & 1 & 9.6 & 1.8 & 1.7 \\
\hline 29 & 9\# coal & 14 & 10 & 0.6 & 14 & 144.2 & 25.2 & 26.4 \\
\hline 30 & Mudstone & 7 & 16.2 & 0.7 & 7 & 78.4 & 5.6 & 12.6 \\
\hline 31 & Siltstone & 9 & 29.4 & 1.6 & 9 & 93.4 & 9.9 & 21.2 \\
\hline 32 & Limestone & 2 & 38.3 & 2.9 & 2 & 19.2 & 3.6 & 3.5 \\
\hline 33 & Fine sandstone & 4 & 37.6 & 2.1 & 4 & 46 & 6 & 6 \\
\hline 34 & Limestone & 3 & 38.3 & 2.9 & 3 & 28.8 & 5.4 & 5.3 \\
\hline
\end{tabular}

$375 \mathrm{~m}$ thick strata to the earth's surface are not modelled but simulated by $148 \mathrm{kN}$ stress using a gravity loading device, as shown in Figure 2. Therefore, in accordance with the vertical geostress gradient, a simulated gravitational force being 148 $\mathrm{kN}$ is adopted. The actual workface advances at the speed of $6 \mathrm{~m} / \mathrm{d}$, and according to similarity theory regarding geometry and time, the extraction height in the physical model is 6 $\mathrm{cm}$, and each excavation at the $6 \mathrm{~cm}$ spacing interval is executed per $2.4 \mathrm{~h}$. On the other hand, a $30 \mathrm{~cm}$ long coal seam is reserved on both sides to eliminate negative consequences induced by boundary effects. The physical model configuration is shown in Figure 2. Also, a set of self-developed spring installations are arranged along the panel floor to emulate the high pressure supported by confined water. Each unit of the spring group comprises two iron plates connected through two springs, and both plates are $30 \mathrm{~cm}, 10 \mathrm{~cm}$, and $1 \mathrm{~cm}$ in length, width, and thickness, respectively. According to Hooke's law and similarity theory, the stress onto the coal seam floor provided by the spring group shall reach $6 \mathrm{MPa}$ prior to model construction.

3.2. Floor Fracture Development. The panel floor undergoes complicated loading and unloading processes due to mining operations. After accumulating and releasing energies, rock mass cracks and various fractures with different dimensions initiate. Such minor secondary fractures would extend and 


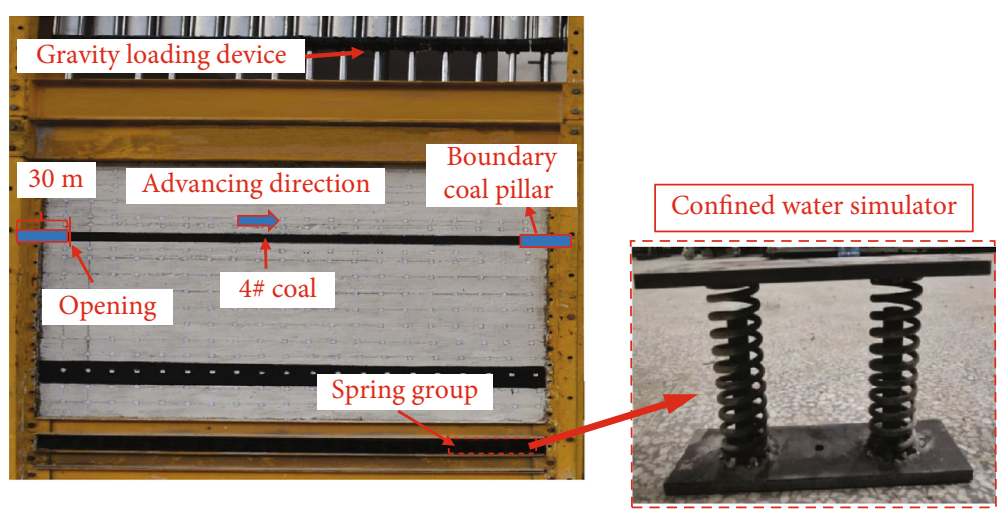

Figure 2: Configuration and components of the physical model.

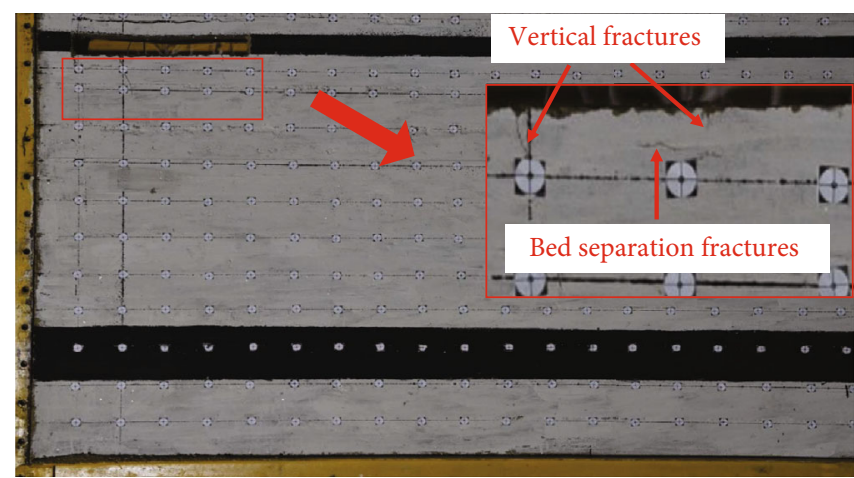

(a)

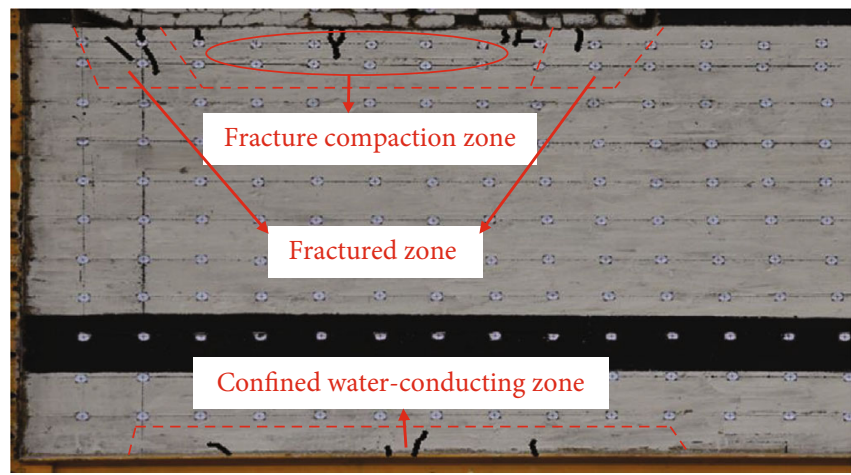

(c)

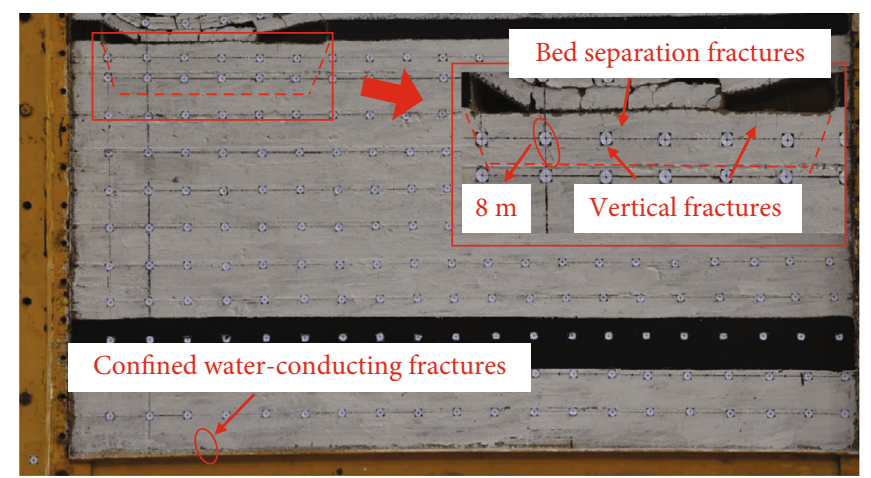

(b)

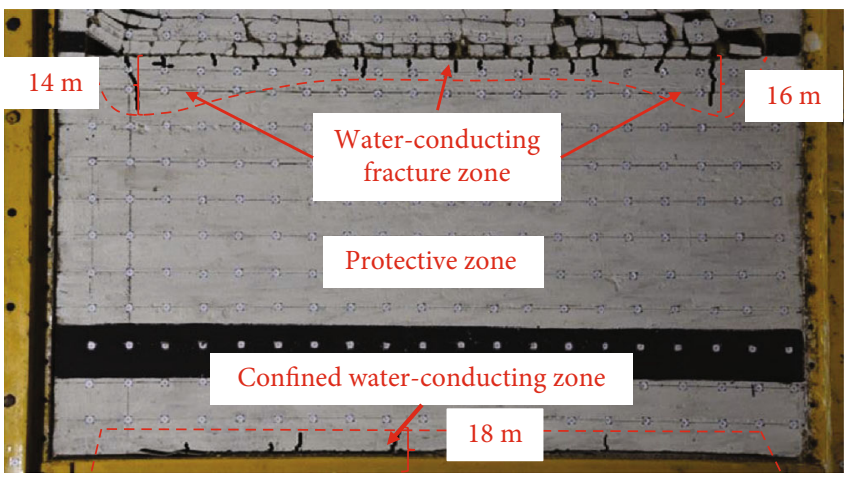

(d)

FIGURE 3: Floor fracturing profile with workface advancing: (a) workface advances $36 \mathrm{~m}$; (b) workface advances $66 \mathrm{~m}$; (c) workface advances $102 \mathrm{~m}$; (d) workface advances $186 \mathrm{~m}$.

expand when subjected to mining disturbance and then tend to converge after overburden collapses. It can be seen from Figure 3(a) that, as the workface advances $36 \mathrm{~m}$, small-scale bedding plane separation comes into being, and in the meantime, such a separation extends $5 \mathrm{~m}$ along the longitudinal direction with vertical fractures thereof reaching $0.1 \mathrm{~m}$ in openness. In the middle of the mined-out area, there are two minor vertical fractures, while the immediate roof is still stable and floor fracture is developing with depth reaching 6 $\mathrm{m}$. As the workface further progresses, roof failure occurs and the fractures forming in the floor area gradually shrink because of the gravity of collapsed overburden strata, as shown in Figure 3(b).

When the fractures at the middle of the void tend to converge, novel fractures initiate in front of the workface and vertical fractures nearby the setup room, go deep, and extend $8 \mathrm{~m}$ approximately. Above the confined water area, there are also a number of minor fractures propagating upward with the workface advancing. When the $102 \mathrm{~m}$ long coal seam is excavated, as shown in Figure 3(c), floor fracture achieves its maximum depth, $14.8 \mathrm{~m}$, and some at the middle of the void are compacted. Figure 3(d) shows that the floor area 


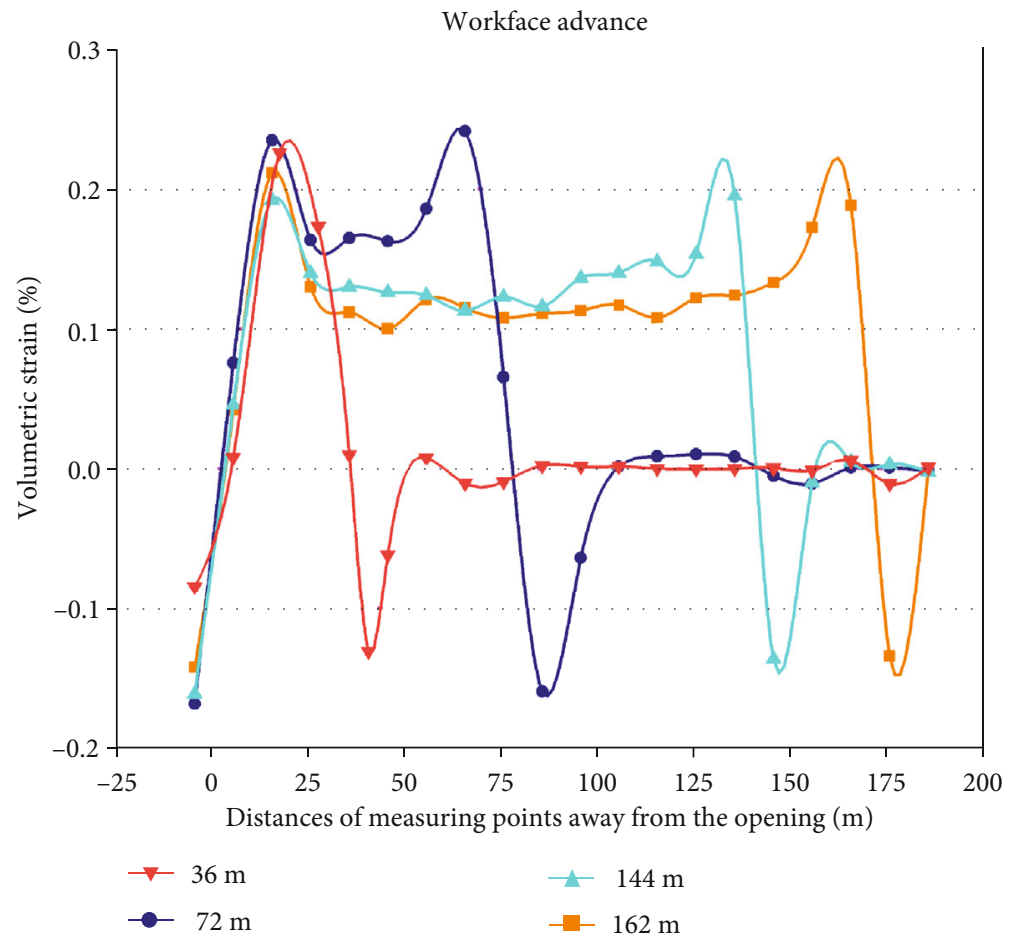

FIgURE 4: Volumetric strain curves of strata $5 \mathrm{~m}$ below the panel floor while mining progresses.

TABLE 2: Choice of volumetric strain-permeability curves.

\begin{tabular}{lcccc}
\hline Name of paper & Lithology & Geological time & Sampling location & Other characteristics \\
\hline Fan et al. [19] & Sandstone & Quaternary & Yili, Xinjiang & Weakly cemented \\
Yu et al. [28] & Red sandstone & Quaternary & Ganzhou, Jiangxi & Ordinary \\
Xia et al. [29] & Sandstone & Carboniferous & Taiyuan, Shanxi & Ordinary \\
\hline
\end{tabular}

Notes: the floor of the studied coal seam is mainly composed of ordinary Carboniferous sandstone, and this coal mine is located in Taiyuan, Shanxi Province.

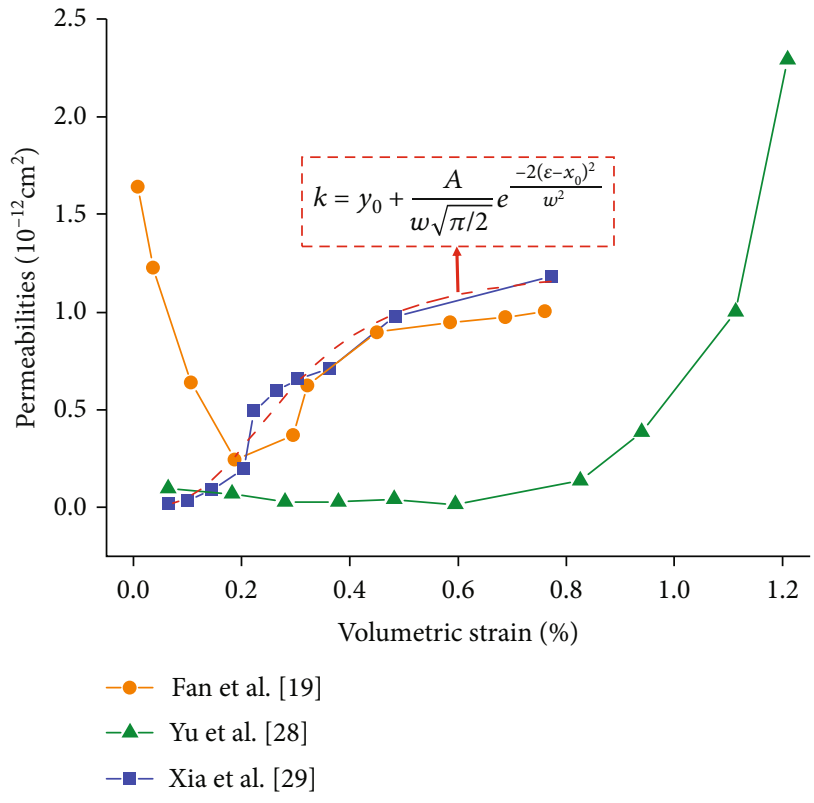

FIGURE 5: Curves of volumetric strain vs. permeability obtained by different scholars. can be divided into three zones from the immediate floor down, including fractured zone, intact water-resisting zone, and confined water-conducting zone. In detail, the fractured zone is like an inverted saddle, reaching its maximum depth in the area below the lateral ribs. Mining-induced fractures in front of the workface are of the greatest developing degree and reach the greatest depth, $16 \mathrm{~m}$ in the vertical direction. In addition, the thickness of the confined water-conducting zone is about $18 \mathrm{~m}$.

3.3. Floor Deformation. The study on bulking deformation can be achieved on the basis of surfaces rather than lines by virtue of an approach, namely, "four-point surrounded area." The bulking deformation ratio determined in this manner shall have more value in application [23]. So, according to the formula of "four-point surrounded area" approach, the volumetric strain of the floor is calculated regardless of the impacts of physical model thickness on volumetric strain in the simulated mining process.

$$
\varepsilon=\frac{S^{\prime}-S}{S},
$$




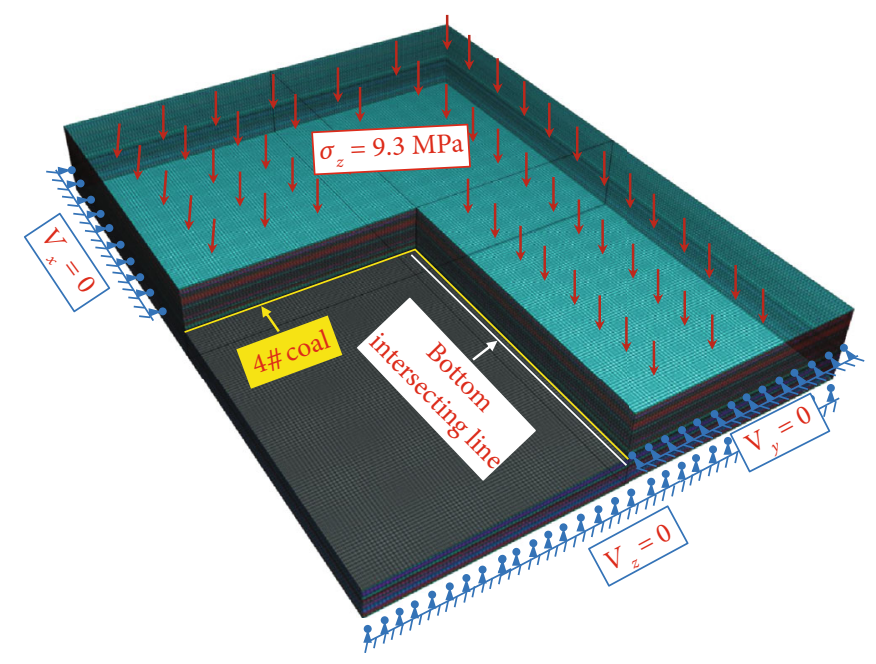

Figure 6: Configuration of the 3D numerical model.

where $\varepsilon$ is the volumetric strain of rock mass; $S$ the area of the coal seam floor before mining, a constant value; and $S^{\prime}$ is the area of the coal seam floor after mining.

As mining operation progresses, floor rocks in different depths see similar variation law in terms of the volumetric strain. Therefore, the layer that is $5 \mathrm{~m}$ below the $4 \#$ coal seam floor is selected and its volumetric strain is analyzed in detail. Relevant data are listed in Figure 4.

When the workface advances $36 \mathrm{~m}$, the rock mass $10 \mathrm{~m}$ behind the opening is compressed because of abutment pressure effect and shows volumetric strain decline, -0.00085 in minimum. Similar impacts can also be demonstrated by floor rocks within $11 \mathrm{~m}$ range in front of the workface, where the frontal abutment pressure makes such rocks compressively deformed and volumetric strain reduced to -0.00131 . At the present time, roof strata have not collapsed and floor strata below the mined-out area are being in a stress unloading state. Considering the tension effect, volumetric strain of the rock mass increases and peaks at 0.00226 . It can be seen that the bulking deformation ratio profile of the panel floor is " $\Lambda$ " shaped. Then, the maximum volumetric strain reaches 0.00241 and the minimum reaches -0.00168 as the workface advances $72 \mathrm{~m}$, where floor rocks in the middle of the mined panel experience slight decrease in volumetric strain due to the gradual compaction of collapsed media. When the $144 \mathrm{~m}$ long coal seam is excavated, the maximum volumetric strain changes to 0.0192 , with the minimum to -0.00149 . The bulking deformation ratio profile shows that its peak value nearby the setup room is lower than that nearby the frontal rib, because the compaction degree of collapsed overburden is higher in the setup room area. Such recompaction of fallen rocks on the panel floor reaches equilibrium, and volumetric strain of floor rocks in the middle of the panel void becomes stable when the workface advances $162 \mathrm{~m}$. Here, the maximum volumetric strain is still distributed in the panel void 7 9 $\mathrm{m}$ behind the frontal rib, with the value peaking at 0.00236 . In contrast, volumetric strain of the coal seam floor $8 \sim 10 \mathrm{~m}$ in front of the workface reaches the lowest, -0.00134 , and the bulking deformation profile extends like an inverted saddle.

\section{Impacts of Mining Parameters on Floor Rock Permeability}

Through the above analysis of floor deformation characteristics in a physically simulated coal mining process, the reason that deformation and failure trigger groundwater loss can be rooted from the changes in floor rock permeability. In fact, the more developed the fractures, the higher the volumetric strain and permeability. In order to investigate the impact degree of different mining parameters on floor rock permeability, three geometric factors regarding panel height, length, and width are selected in the context of the $4 \#$ coal seam of the Longquan coal mine. Such investigation results are of significant value in supporting theoretical references to the panel geometry setting under the condition of waterconserved mining.

4.1. Volumetric Strain-Permeability Curve Fitting. In order to characterize the change of permeability under hydraulic coupling, different scholars have established many theoretical models based on the assumption of small elastic deformation [24-27]. However, in order to study the permeability evolution of the mining floor, some scholars will use the volume strain permeability relationship to study $[28,29]$. Fan et al. conducted an experimental study on the permeability of weakly cemented sandstone and obtained the relationship between volumetric strain and permeability of weakly cemented rocks [19]. Similarly, Yu et al. [30] studied the permeability property of rock samples along different stress paths and obtained a curve of sandstone. Other curves for Carboniferous rocks drilled from North China were also obtained by Xia et al. [31] by means of servo permeability tests. The lithological characteristics of different rock samples and their corresponding volumetric strain-permeability curves are shown in Table 2 and Figure 5, respectively.

As mentioned in Table 2, the floor of the 4\# coal seam in the Longquan coal mine is mainly composed by sandstone and it can be seen that the sampling location and geological time of studied floor rocks in this paper have a good 


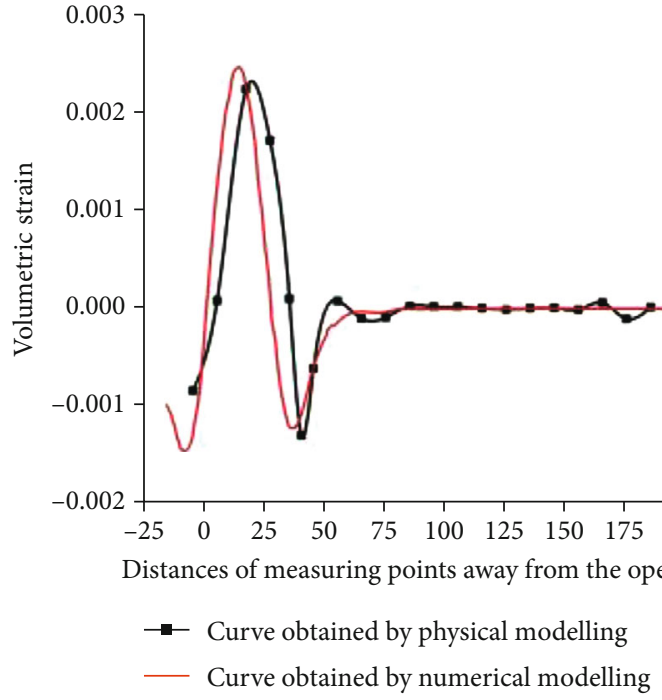

(a)

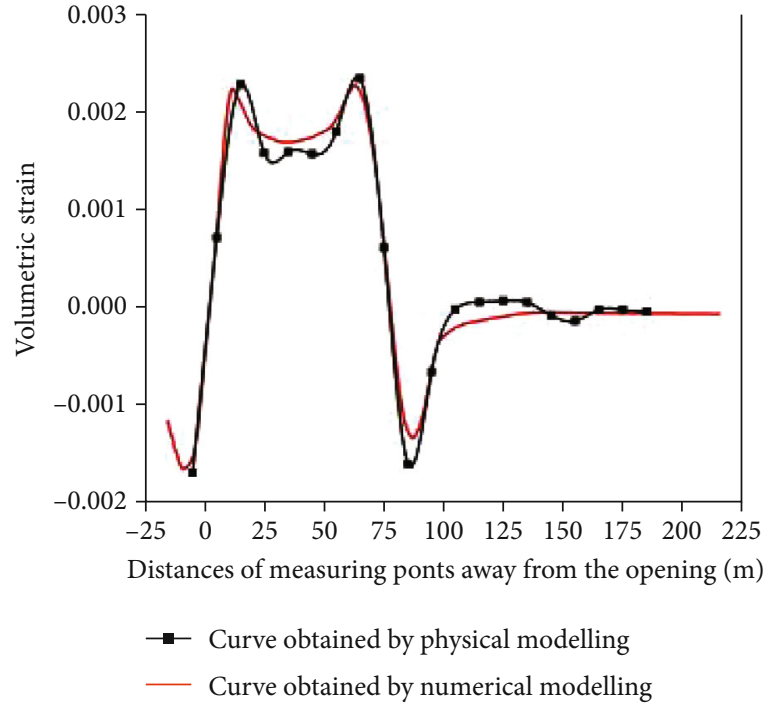

(b)

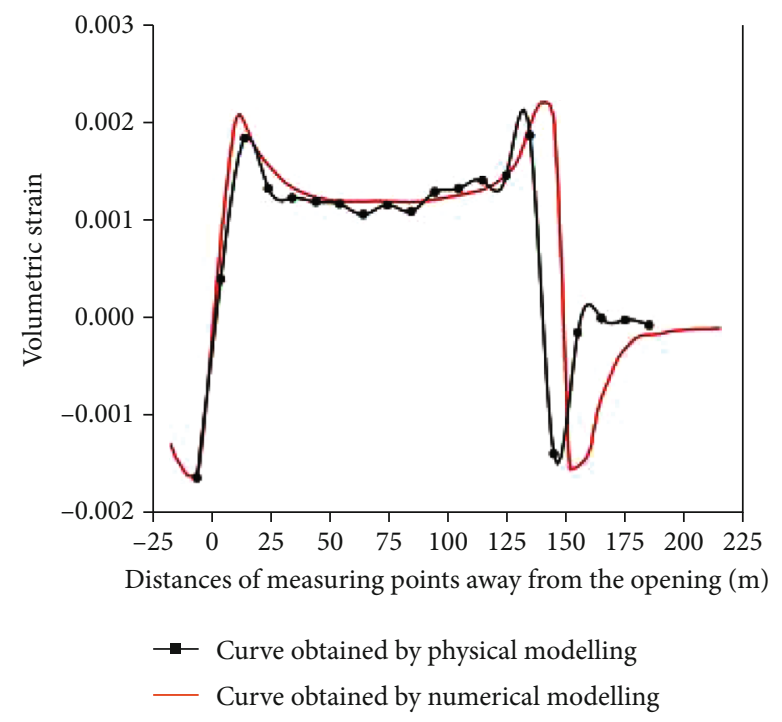

(c)

Figure 7: Comparison of volumetric strain obtained by physical modelling and numerical modelling in different advancing distances: (a) workface advances $36 \mathrm{~m}$; (b) workface advances $72 \mathrm{~m}$; (c) workface advances $144 \mathrm{~m}$.

agreement with those in the paper [29]. Therefore, the curve of sandstone volumetric strain and permeability obtained by Xia et al. is fitted by virtue of Gaussian function, which gives the results as

$$
k=y_{0}+\frac{A}{w \sqrt{\pi / 2}} e^{-2\left(\varepsilon-x_{0}\right)^{2} / w^{2}}
$$

where $k$ is the permeability and $\varepsilon$ is the volumetric strain, and for other constant parameters, there are $y_{0}=2.53944 \times 10^{-12}$, $A=-4.3916 \times 10^{-13}, w=0.13984$, and $x_{0}=-0.04739$.

4.2. Numerical Modelling. The 3D numerical model established via the FLAC3D software is shown in Figure 6 [32]. The model is $2000 \mathrm{~m}, 1500 \mathrm{~m}$, and $252 \mathrm{~m}$ in length, width, and height, respectively. The top surface bears a vertical
TABLE 3: Schemes of numerical simulation.

\begin{tabular}{lccc}
\hline Scheme & Panel height $(\mathrm{m})$ & Panel width $(\mathrm{m})$ & Panel length $(\mathrm{m})$ \\
\hline 1 & 4 & 250 & 800 \\
2 & 6 & 250 & 800 \\
3 & 8 & 250 & 800 \\
4 & 4 & 500 & 800 \\
5 & 4 & 750 & 800 \\
6 & 4 & 250 & 1000 \\
7 & 4 & 250 & 1200 \\
\hline
\end{tabular}

stress of $9.3 \mathrm{MPa}$, and the bottom bears a water pressure of $6 \mathrm{MPa}$. In addition, the displacement of the bottom and four laterals are fixed; this numerical model shares the same stratigraphic sequence with the above constructed physical 


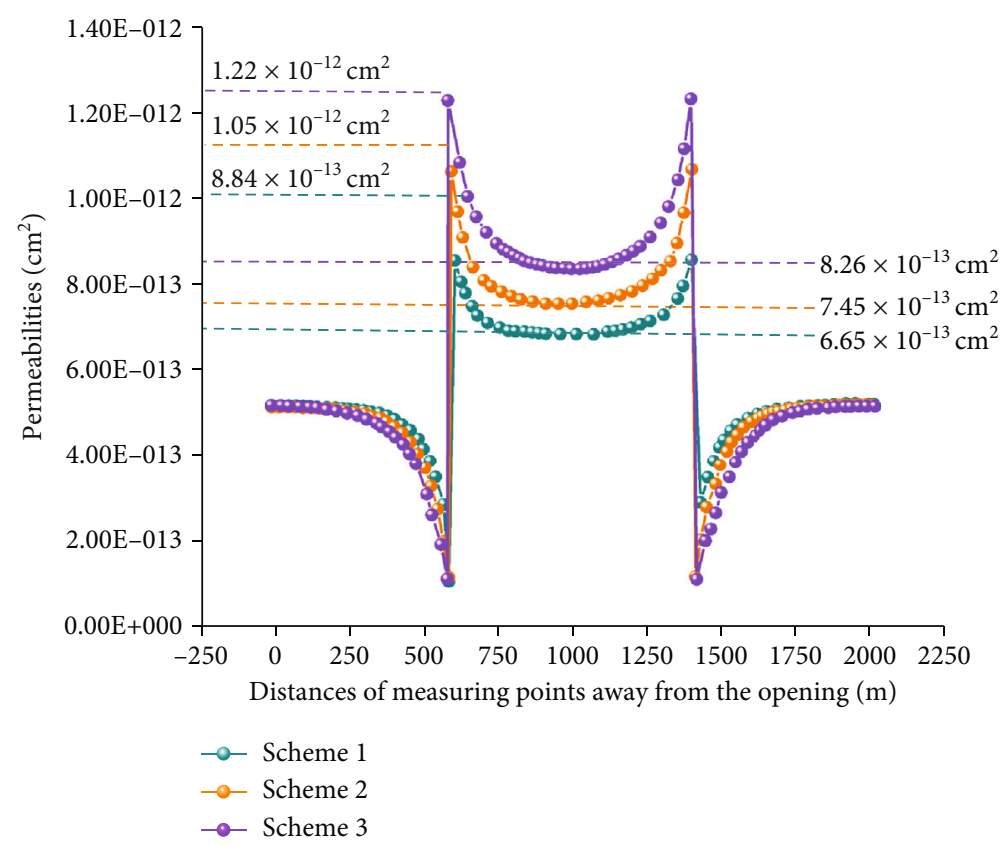

FIGURE 8: Curve of floor permeability in response to different panel heights.

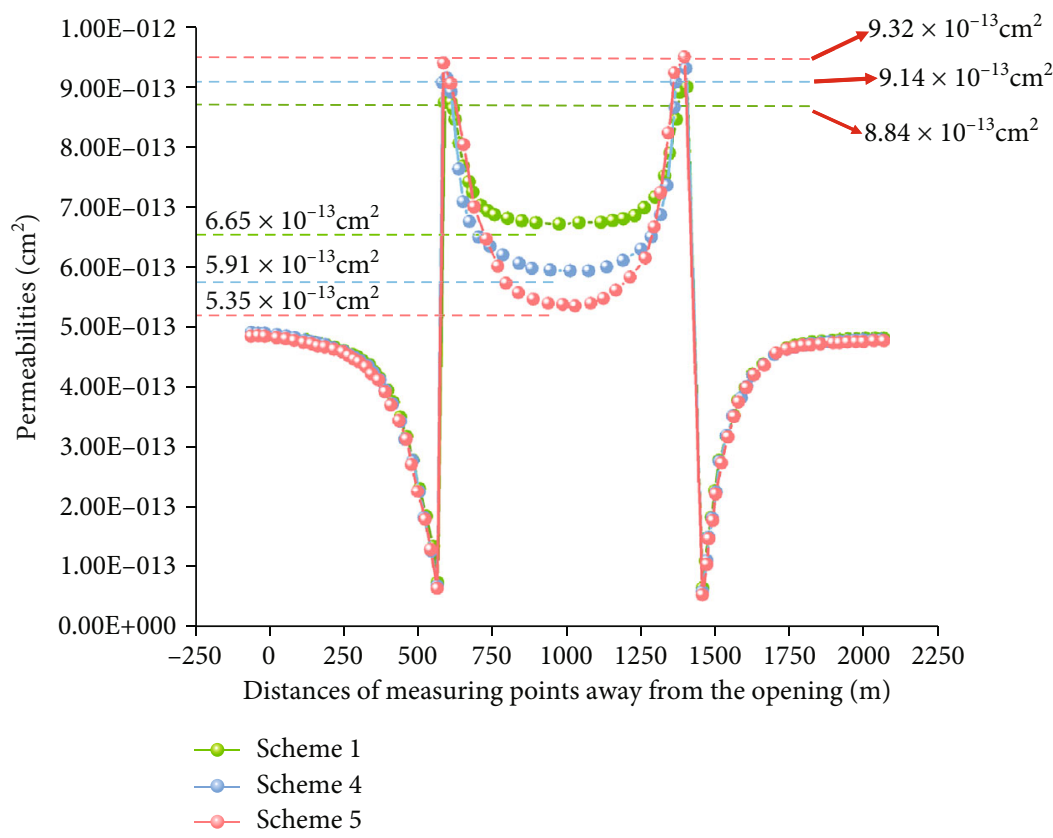

FIGURE 9: Curve of floor permeability in response to different panel widths.

model. A monitoring line is placed $5 \mathrm{~m}$ below the coal seam-rock floor interface to collect the volumetric strain variation of floor rocks. The purpose of this operation is to verify the appropriateness and rationality of the numerical model by a volumetric strain indicator. The curve describing the volumetric strain variation with coal seam excavation is shown in Figure 7.

The volumetric strain obtained by numerical modellingbased computation in three excavation periods is compared with that by physical modelling. The results show that the maximum volumetric strain reaches 0.00241 when the panel works $36 \mathrm{~m}$, with the minimum reaching -0.00155 . In the case of $72 \mathrm{~m}$, the volumetric strain of the floor in the middle of the panel void decreases, while that in the rib area is the highest, reaching 0.00231, and that below both lateral coal bodies is the lowest, reaching -0.00164. As the workface advances $144 \mathrm{~m}$, the maximum and minimum volumetric strains are 0.0229 and -0.00166 , respectively. In general, the greatest difference ratio of the numerical model to the physical model only accounts for $6.6 \%$, and both curves share a similar evolution trend, suggesting a good agreement between both models. 


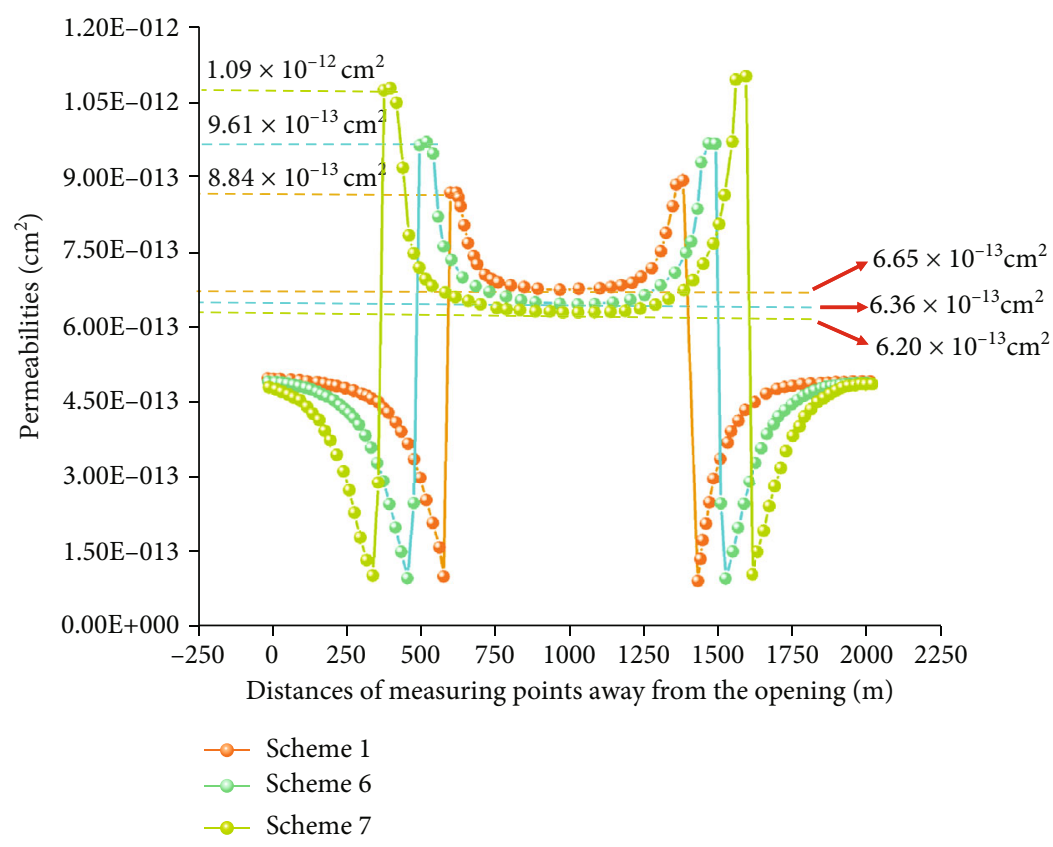

Figure 10: Curve of floor permeability in response to different panel lengths.

Formula (2) is input into the FLAC3D software to study the impacts of panel height, width, and length on floor permeability. According to the geological conditions of the $4 \#$ coal seam, panel height is considered $4 \mathrm{~m}, 6 \mathrm{~m}$, and $8 \mathrm{~m}$, respectively, with panel width $250 \mathrm{~m}, 500 \mathrm{~m}$, and $750 \mathrm{~m}$ and panel length $800 \mathrm{~m}, 1000 \mathrm{~m}$, and $1200 \mathrm{~m}$. There are totally 7 simulation schemes in line with the approach, namely, single variable control. Such designed schemes can be compared with each other to analyze the impacts of different panel geometries on floor permeability. So a measuring line is arranged $5 \mathrm{~m}$ below the coal seam floor to obtain the permeability of the rock blocks with the centroid located along this line. The maximum value amongst calculated permeability is taken to participate in the subsequent comparison. Simulation schemes are listed in Table 3.

4.3. Simulation Result Analysis. Figure 8 shows that, when the two horizontal geometries (panel length and width) are considered fixed, the maximum permeability of floor rocks reaches $8.84 \times 10^{-13} \mathrm{~cm}^{2}$ in the case of $4 \mathrm{~m}$ panel height, while this value increases to $1.06 \times 10^{-12} \mathrm{~cm}^{2}$ in $6 \mathrm{~m}$ panel height and then to $1.22 \times 10^{-12} \mathrm{~cm}^{2}$ in $8 \mathrm{~m}$ panel height. It can be seen that there is a positive correlation between the maximum permeability of floor rocks and panel height. In fact, the minimum permeability also sees the same variation law due to the results that it reduces from $6.65 \times 10^{-13} \mathrm{~cm}^{2}$ to $7.45 \times 10^{-13} \mathrm{~cm}^{2}$ and to $8.26 \times 10^{-13} \mathrm{~cm}^{2}$ with panel height increasing from $4 \mathrm{~m}$ and $6 \mathrm{~m}$ to $8 \mathrm{~m}$. It is speculated that for the same horizontal geometries, greater panel height gives rise to stronger depressurization effect on floor rocks. The compaction degree of collapsed overburden onto the panel floor becomes lower, and the permeability goes higher as a consequence.
The other scenario is shown in Figure 9, in which panel width changes along a gradient, but other geometries including panel height and length are fixed. The results show that the maximum permeability of floor rocks goes higher as panel width enlarges: $8.84 \times 10^{-13} \mathrm{~cm}^{2}$ in $250 \mathrm{~m}$ panel width, $9.14 \times 10^{-13} \mathrm{~cm}^{2}$ in $500 \mathrm{~m}$ panel width, and $9.32 \times 10^{-13} \mathrm{~cm}^{2}$ in $750 \mathrm{~m}$ panel width. However, its impact on permeability changes is weaker than the above analyzed factor, panel height. There is a totally different phenomenon in terms of the minimum permeability that decreases from $6.65 \times 10^{-13}$ $\mathrm{cm}^{2}$ in $250 \mathrm{~m}$ panel width to $5.91 \times 10^{-13} \mathrm{~cm}^{2}$ in $500 \mathrm{~m}$ panel width and then to $5.35 \times 10^{-13} \mathrm{~cm}^{2}$ in $750 \mathrm{~m}$ panel width. The reason behind it accords with the impact of panel length on floor permeability.

The last scenario is shown in Figure 10; when the two geometries regarding panel height and width are fixed, the maximum permeability of floor rocks reaches $8.84 \times 10^{-13} \mathrm{c}$ $\mathrm{m}^{2}$ in the case of $800 \mathrm{~m}$ panel length. This value increases to $9.61 \times 10^{-13} \mathrm{~cm}^{2}$ in $1000 \mathrm{~m}$ panel length and then to 1.09 $\times 10^{-12} \mathrm{~cm}^{2}$ in $1200 \mathrm{~m}$ panel length. In general, the impact of such a geometric factor is still weaker than that of panel height. The minimum permeability of the compressed area below the panel void demonstrates a different trend, with the value reducing from $6.20 \times 10^{-13} \mathrm{~cm}^{2}$ to $6.36 \times 10^{-13} \mathrm{c}$ $\mathrm{m}^{2}$ and to $6.65 \times 10^{-13} \mathrm{~cm}^{2}$. The phenomenon that the minimum permeability of floor rocks decreases with the increase in panel length can be attributed to the wider scope for collapsed overburden, which makes the compaction onto the panel floor stronger, and the minimum value of floor permeability is resultantly lower.

In general, the three geometric factors including panel height, length, and width affect floor permeability to different extents. Comparison results show that the impact degree of panel height is the highest, followed by panel length and width. 


\section{Conclusion}

Based on the case regarding panel 4301 of the Longquan coal mine, the paper establishes a physical model for capturing panel floor failure characteristics. Floor fractures experience three stages including initiation, propagation, and convergence with the workface progressing. Two ribs witness the strongest fracturing behavior, where the fractures extend to the depth of $16 \mathrm{~m}$. The fractures developing at the middle of goaf gradually converge due to caved rock reconsolidation. The fractured zone presents an inverted saddle shape in the floor area.

With coal seam excavation, the volumetric strain of floor rocks experiences a decrease-increase-decrease sequence. Before roof caving, the floor rocks below the middle of goaf have the maximum volumetric strain; after roof caving, two areas at an 8-10 m distance from two ribs exhibit the maximum volumetric strain. The volumetric strain profile changes from $\Lambda$ shape to an inverted saddle shape.

Deformation and failure characteristics of floor rocks show that the more developed the floor fractures, the higher the floor permeability. The paper investigates the impact of panel height, panel length, and panel width on floor permeability by a fitted volumetric strain-permeability equation. The numerical modelling results indicate that the impact degree of panel height ranks first, followed by panel length and panel width.

\section{Data Availability}

The data of this manuscript is tested in the laboratory of State Key Laboratory of Coal Resources and Safe Mining, China University of Mining and Technology, which is available to authorized users.

\section{Conflicts of Interest}

The authors declare that they have no conflicts of interest.

\section{Acknowledgments}

The authors are grateful to the Longquan coal mine in Shanxi for the support. This work was financially supported by the National Natural Science Foundation (grant number 51774268), the Key Research and Development Project of Shanxi Province (grant number 20201101009), the Assistance Program for Future Outstanding Talents of China University of Mining and Technology (grant number 2020WLJCRCZL96), and the Postgraduate Research \& Practice Innovation Program of Jiangsu Province.

\section{References}

[1] Q. Wu, B. X. Hu, L. Wan, and C. M. Zheng, "Coal mine water management: optimization models and field application in North China," Hydrological Sciences Journal, vol. 55, no. 4, pp. 609-623, 2010.

[2] J. H. He, W. P. Li, and W. Qiao, "P-H-q evaluation system for risk assessment of water inrush in underground mining in North China coal field, based on rock-breaking theory and water-pressure transmission theory," Geomatics, Natural Hazards and Risk, vol. 9, no. 1, pp. 524-543, 2018.

[3] M. R. Hasan, H. Rashid, and A. K. Paul, "Environmental impact of coal mining: a case study on Barapukuria coal mining industry, Dinajpur, Bangladesh," Journal of Environmental Science and Natural Resources, vol. 6, no. 2, pp. 207-212, 2015.

[4] J. S. Caine, J. Evans, and C. B. Forster, "Fault zone architecture and permeability structure," Geology, vol. 24, no. 11, pp. 10251028, 1996.

[5] D. L. Dong, W. J. Sun, and S. Xi, "Water-inrush assessment using a GIS-based Bayesian network for the 12-2 coal seam of the Kailuan Donghuantuo coal mine in China," Mine Water and the Environment, vol. 31, no. 2, pp. 138-146, 2012.

[6] B. L. Zhang and Z. B. Meng, "Experimental study on floor failure of coal mining above confined water," Arabian Journal of Geosciences, vol. 12, no. 4, p. 114, 2019.

[7] L. M. Yin, K. Ma, J. T. Chen, Y. C. Xue, Z. Q. Wang, and B. Q. Cui, "Mechanical model on water inrush assessment related to deep mining above multiple aquifers," Mine Water and the Environment, vol. 38, no. 4, pp. 827-836, 2019.

[8] S. Aghababaei, G. Saeedi, and H. Jalalifar, "Risk analysis and prediction of floor failure mechanisms at longwall face in Parvadeh-I coal mine using rock engineering system (RES)," Rock Mechanics and Rock Engineering, vol. 49, no. 5, pp. 1889-1901, 2016.

[9] H. F. Lu, X. Y. Liang, N. Shan, and Y.-K. Zhang, "Study on the stability of the coal seam floor above a confined aquifer using the structural system reliability method," Geofluids, vol. 2018, Article ID 9580271, 15 pages, 2018.

[10] W. T. Liu, D. R. Mu, X. X. Xie, L. Yang, and D. W. Wang, "Sensitivity analysis of the main factors controlling floor failure depth and a risk evaluation of floor water inrush for an inclined coal seam," Mine Water and the Environment, vol. 37, no. 3, pp. 636-648, 2018.

[11] Y. L. Lu and L. G. Wang, "Numerical modeling of mininginduced fracturing and flow evolution in coal seam floor based on micro-crack growth," Journal of Mining \& Safety Engineering, vol. 32, pp. 889-897, 2015.

[12] Y. B. Hu, W. P. Li, Q. Q. Wang, S. L. Liu, and Z. K. Wang, "Evolution of floor water inrush from a structural fractured zone with confined water," Mine Water and the Environment, vol. 38, no. 2, pp. 252-260, 2019.

[13] Z. Z. Liang, W. C. Song, and W. T. Liu, "Theoretical models for simulating the failure range and stability of inclined floor strata induced by mining and hydraulic pressure," International Journal of Rock Mechanics and Mining Sciences, vol. 132, p. 104382, 2020.

[14] G. Fan, M. Chen, D. Zhang et al., "Experimental study on the permeability of weakly cemented rock under different stress states in triaxial compression tests," Geofluids, vol. 2018, Article ID 9035654, 9 pages, 2018.

[15] J. Heiland, "Permeability of triaxially compressed sandstone: influence of deformation and strain-rate on permeability," Pure and Applied Geophysics, vol. 160, no. 5-6, pp. 889-908, 2003.

[16] S. Harpalani and G. L. Chen, "Influence of gas production induced volumetric strain on permeability of coal," Geotechnical \& Geological Engineering, vol. 15, no. 4, pp. 303-325, 1997.

[17] S. A. Mathias, S. Nielsen, and R. L. Ward, "Storage coefficients and permeability functions for coal-bed methane production under uniaxial strain conditions," Transport in Porous Media, vol. 130, no. 2, pp. 627-636, 2019. 
[18] M. Hamoud, R. Chalaturnyk, and J. Leung, "Experimental studies of shear-induced changes in two-phase relative permeability," Arabian Journal of Geosciences, vol. 13, no. 14, p. 686, 2020.

[19] G. W. Fan, S. Z. Zhang, B. B. Cao, D. S. Zhang, and C. G. Zhang, "Impact of mine panel size on hydraulic permeability of weakly cemented strata," Sustainability, vol. 12, no. 6, p. 2396, 2020.

[20] T. R. C. Aston, R. N. Singh, and B. N. Whittaker, "The effect of test cavity geology on the in situ permeability of coal measures strata associated with longwall mining," International Journal of Mine Water, vol. 2, no. 4, pp. 19-34, 1983.

[21] D. P. Adhikary and H. Guo, "Modelling of longwall mininginduced strata permeability change," Rock Mechanics and Rock Engineering, vol. 48, no. 1, pp. 345-359, 2015.

[22] M. Khanal, H. Guo, and D. Adhikary, "3D numerical study of underground coal mining induced strata deformation and subsequent permeability change," Geotechnical and Geological Engineering, vol. 37, no. 1, pp. 235-249, 2019.

[23] A. P. He, H. Fu, Y. B. Lu, and B. J. Huo, "Analysis method on swelling deformation of protected seam in the process of protective coal seam exploitation," Journal of Safety Science and Technology, vol. 12, no. 8, pp. 60-67, 2016.

[24] Y. Xue, T. Teng, F. N. Dang, Z. Y. Ma, S. H. Wang, and H. B. Xue, "Productivity analysis of fractured wells in reservoir of hydrogen and carbon based on dual-porosity medium model," International Journal of Hydrogen Energy, vol. 45, no. 39, pp. 20240-20249, 2020.

[25] J. Liu, X. Liang, Y. Xue, K. Yao, and Y. Fu, "Numerical evaluation on multiphase flow and heat transfer during thermal stimulation enhanced shale gas recovery," Applied Thermal Engineering, vol. 178, article 115554, 2020.

[26] Z. L. Fan, G. W. Fan, D. S. Zhang et al., "Optimal injection timing and gas mixture proportion for enhancing coalbed methane recovery," Energy, vol. 222, article 119880, 2021.

[27] Z. L. Fan, D. S. Zhang, G. W. Fan et al., "Non-Darcy thermalhydraulic-mechanical damage model for enhancing coalbed methane extraction," Journal of Natural Gas Science and Engineering, vol. 98, p. 104048, 2021.

[28] Z. J. Lu and S. Z. Li, "Experimental study on permeability and strain characteristics of coal containing gas," Safety in Coal Mines, vol. 51, no. 6, pp. 1-4, 2020.

[29] X. Chen, C. A. Tang, J. Yu, J. F. Zhou, and Y. Y. Cai, "Experimental investigation on deformation characteristics and permeability evolution of rock under confining pressure unloading conditions," Journal of Central South University, vol. 25, no. 8, pp. 1987-2001, 2018.

[30] J. Yu, S. J. Chen, X. Chen, Y. Z. Zhang, and Y. Y. Cai, “Experimental investigation on mechanical properties and permeability evolution of red sandstone after heat treatments," Journal of Zhejiang University-SCIENCE A, vol. 16, no. 9, pp. 749-759, 2015.

[31] X. H. Xia, W. F. Yang, D. W. Cui, L. T. Liu, J. J. Zhao, and P. P. Zhao, "Test study on penetrabillty of floor rock in stope," Mining Safety \& Environmental Protection, vol. 33, no. 22, pp. 2022, 2006.

[32] S. Z. Zhang, G. W. Fan, S. Y. Jiang, Z. L. Fan, S. D. Li, and H. N. $\mathrm{Ni}$, "Dual-hazard control mechanism of burst-prone and spontaneous combustion coalface considering effect of retreat speed," Energy Reports, vol. 7, pp. 278-288, 2021. 